\title{
Comparative characteristics of stress-resistant and non- stress-resistant individual profiles
}

\section{Características comparativas de perfiles individuales resistentes a tensiones y no resistentes a tensiones}

\author{
Sergii Boltivets \\ State Institute of Family and Youth Policy of Ukraine, Kyiv, Ukraine \\ ORCID: https://orcid.org/0000-0003-4432-5272

\section{Mykola Korolchuk} \\ Kyiv National University of Trade and Economics, Kyiv, Ukraine \\ ORCID: https://orcid.org/0000-0001-7121-3474

\section{Valentyna Korolchuk} \\ Kyiv National University of Trade and Economics, Kyiv, Ukraine \\ ORCID: https://orcid.org/0000-0002-1147-3095

\section{Sergii Myronets} \\ Kyiv National University of Trade and Economics, Kyiv, Ukraine \\ ORCID: https://orcid.org/0000-0002-9185-3206

\section{Yevhen Pozdnyshev}

Kyiv National Economic University named after Vadym Hetman, Kyiv, Ukraine ORCID: https://orcid.org/0000-0003-3686-1753

\section{* Correspondence}

Email:boltivetssergi@i.ua

\section{Citation:}

S. Boltivets, M. Korolchuk, V. Korolchuk, S.Myronets, Ye.Pozdnyshev (2021). Comparative characteristics of stressresistant and non-stress-resistant individual profiles, Propósitos y Representaciones, 9(SPE2), e1102. http://dx.doi.org/10.20511/pyr2021.v9nSPE2.1102 


\section{Summary}

The article presents typical profiles of stress-resistant and non-stress-resistant individuals by certain components. Summarizing the factor analysis substantive elements, we identified four leading components of the internal structure of indicators of personality stress relationships by the informative weight of variables: personal; social; typological, and behavioral. We found out that stress-resistant individuals are characterized by a high level of balance, confidence and activity, emotional and volitional self-control, low levels of stress, personal and situational anxiety, high levels of motivation, general and professional internality, readiness for activity, high level of functional system. Stress-resistant individuals are characterized by a high level of assertiveness, activity, prosociality, the search for social contacts and social support. At the same time, the typical profile of non-stressful individuals is characterized by inverse patterns - a significantly lower level of direct and indirect indicators of stress resistance, among the behavioral strategies for overcoming stress typical in the profile were manipulative actions, avoidance actions, aggressive actions.

Keywords: Stress resistance; Structural components of stress resistance; Factors; TypesFactores; Tipos.

\section{Resumen}

El artículo presenta perfiles típicos de individuos resistentes y no resistentes al estrés por determinados componentes. Resumiendo los elementos sustantivos del análisis factorial, identificamos cuatro componentes principales de la estructura interna de los indicadores de relaciones de estrés de personalidad por el peso informativo de las variables: personal; social; tipológico y conductual. Descubrimos que los individuos resistentes al estrés se caracterizan por un alto nivel de equilibrio, confianza y actividad, autocontrol emocional y volitivo, bajos niveles de estrés, ansiedad personal y situacional, altos niveles de motivación, interioridad general y profesional, disposición para actividad, alto nivel de sistema funcional. Los individuos resistentes al estrés se caracterizan por un alto nivel de asertividad, actividad, prosocialidad, búsqueda de contactos sociales y apoyo social. Al mismo tiempo, el perfil típico de los individuos no estresantes se caracteriza por patrones inversos: un nivel significativamente menor de indicadores directos e indirectos de resistencia al estrés, entre las estrategias de comportamiento para superar el estrés típicas en el perfil se encuentran acciones manipuladoras, acciones de evitación, acciones agresivas.

Palabras clave: Resistencia al estrés; Componentes estructurales de la resistencia al estrés;

\section{Introduction}

The problem of resistance to stress is becoming more scientifically and practically important because of the dynamic changes in the economic, military, political, and other spheres of society. The study of stress in connection with the undeclared war of Russian mercenaries against the Ukrainian people, the occupation of Ukrainian territories, which causes an unstable internal socio-political and economic situation (Yankovyi et al., 2020) and leads to stress and negatively affects the mental and physical health of the individual becomes significantly important. Stress impacts permeate our entire modern lives of all categories of the population and professionals and require multi-vector research on psychodiagnostic to overcome and prevent negative consequences. 
Most of both national (Krainyuk, Myronets, Timchenko, Korolchuk M., Osyodlo, etc.) and foreign scientific research on the problem of stress (Lazarus R., Parker J., Perrez M., Reicherts M.) is devoted mainly to one of the topics: theoretical, research, diagnostic or psychological intervention issues. At the same time, the resistance of the individual to stress is an urgent problem. Identification of features and comparative analysis of profiles of stressresistant and non-stress-resistant people will allow determining adequate psychodiagnostic tools, psychoprophylaxis and psychotherapy of specialists for risky professions and, in particular, rescuers.

At the same time, taking into account all the achievements of modern science and practice, a comparative analysis of the profiles of stress-resistant and non-stress-resistant individuals was not considered a direct statement, comprehensively identifying structural components, psychodiagnostic tools and manifestation.

The main purpose of the study is to determine the typical manifestations and features of stress-resistant and non-stress-resistant professionals. This involves solving two additional problems that can be combined in this research topic. First, to find out the psychological characteristics of stress in different categories of examined. Second, to characterize the typical profiles of stress-resistant and non-stress-resistant individuals.

\section{Methods, procedure, participants}

In justifying the choice of methods for the study of personality stress, we proceeded from the fact that stress has structural elements with different levels of an organization.

We performed psychodiagnostics of stress resistance according to a set of direct and indirect indicators.

The level of stress resistance was measured by direct indicators of methods that determine the self-assessment of stress resistance, the level of stress resistance, autonomic manifestations of stress, comprehensive assessment of stress, behavioral strategies to overcome stress.

Research of side indicators, considered as manifestations of stress resistance in motivational, personal, social and behavioral spheres, should be carried out according to a set of informative indicators of methods aimed at studying: mental states, locus of control, level of self-esteem, volitional qualities, activity, volitional self-regulation. personal anxiety, maladaptive behavior, as well as individual psychological characteristics: self-esteem, level of demands, motivation for professional activity, motivation to achieve, motivation for approval, properties of the nervous system.

The study of the level of primary (basic) stress resistance was carried out according to the methods of assessing the functional properties of the nervous system, which were carried out in conditions of intense sound and light effects.

To clarify the characteristics of stress-resistant and non-stress-resistant individuals and the content of typical profiles, we made comparative characteristics of the stress resistance components. Comparative analysis was performed on data obtained from a set of direct and indirect indicators of methods. According to the identified components of stress resistance and direct indicators, we analyzed the stress resistance characteristics of the individual in a sample of 189 people. 


\section{Research results}

The division into stress-resistant and non-stress-resistant was carried out according to the most informative method of studying stress resistance by S. Cowhen and G. Williamson (1991).

Based on the analysis of the obtained data on a set of methods of direct indicators of stress resistance "Self-assessment of stress resistance by S. Cowhen and G. Williamson", "Test for stress resistance", "Comprehensive assessment of stress", we obtained a direct measurement of stress resistance, which allowed to characterize stress characteristics and typical profiles of stress-resistant and non-stress-resistant individuals. A general pattern has been established, which is that a person's stress resistance is determined by indicators of stress level (high, medium, low, very low); the level of basic, integral and dynamic stress sensitivity and stress indicators, which is due to the signs of stress in the professional, emotional and physiological spheres. Stress-resistant individuals have a high or medium level of stress resistance; low levels of basic, dynamic and integral stress sensitivity, high ability to resist and find constructive strategies to overcome stress and its compensation. Peculiarities of non-stress-resistant subjects are manifested in a high level of basic, dynamic, and integral stress sensitivity, increased response to circumstances that cannot be influenced, the tendency to complicate.

Summing up the characteristics of stress-resistant individuals, we found that the main strategies in the structural mechanism of coping with stress are expressed in assertiveness, activity, prosociality, seeking social support and joining social contacts, along with a medium level of caution and low level of manipulation, asociality, aggression. The main strategies for overcoming stress in non-stress groups are significantly lower - assertive actions, prosociality, activity, seeking social support, joining social contact. There is a general pattern of behavioral strategies in coping with stress for people with high and low levels of stress resistance; the main strategies for coping with stress are assertiveness, activity, prosociality, seeking social support and social contact, the severity of which determines adequacy or inadequacy, success or failure in coping with stress and affects the stress resilience of the individual.

The comparative analysis of correlations for direct indicators of stress resistance of the examined gives evidence to the informativeness of the methods indicators and the need to use them to diagnose stress resistance. According to the degree of informativeness, the indicators of the methods are arranged as follows: first, stress resistance according to the method of "Selfassessment of stress resistance" (Cowhen and Williamson, 1991); secondly, an integrated indicator of behavioral strategies in coping with stress by the method of "Overcoming stress" (Hobfall, 1989); thirdly, the indicator of stress sensitivity according to the method of "Test for stress resistance" (Shcherbatykh, 2000) and detection of stress manifestations according to the method of "Comprehensive assessment of stress manifestations" (Shcherbatykh, 2000) and "Vegetative manifestations of stress" Scraped).

Summarizing the substantive elements of factor analysis, we have identified, according to the informative weight of the variables, four leading components of the internal structure of the relationship of personality stress indicators: factor F1 - personal; factor F2 - social; factor F3 typological and factor F4 - behavioral.

In general, it is necessary to note the features of stress resistance for three categories of rescuers (experienced, less experienced, and inexperienced) according to the comparative characteristics of results according to the block of informative methods of psychodiagnostics, which was identified based on correlation analysis. 
A general pattern has been created, which according to direct indicators of stress resistance and analysis of the distribution of rescuers in groups according to evaluation criteria is that the level of stress resistance increases with the level of professional competence (experience) increasing. The average level of stress resistance in the group of inexperienced is observed at the level of $11.9 \pm 0.4$ (with high and medium level for $47 \%$ of subjects; with satisfactory - $36 \%$; with low and very low $-17 \%$ of people); similarly in the group of inexperienced the level of stress resistance - $9.2 \pm 0.3$ (with high and medium level - 66\%, and with satisfactory and low 34\%) and in the group of experienced the level of stress resistance is the highest $-5.7 \pm 0.2$ (the lower value, the higher the level of stress resistance). With high and medium scores $-90 \%$, with satisfactory - $10 \%$, which indicates the features and significant impact of professional competence on stress resistance for different categories of rescuers.

We found that coping strategies for professionals are active, prosocial, constructive. This is due to the high level of stress resistance, low level of personal anxiety, high level of emotional and volitional control in combination with the positive use of social resources (contacts, support), which provides a high level of stress resistance for experienced rescuers.

Based on the interpretation of the results of the study, the model of behavior of experienced rescuers is characterized by activity, prosociality, self-control, willingness to work, and professional internality (variables that are decisive in the structural mechanism of stress regulation).

Features of inexperienced rescuers are that the level of stress resistance in this group is $9.2 \pm 0.3$ points, which is 3.7 points worse than the experienced and 2.7 points better than the inexperienced $(\mathrm{p}<0,05)$. According to the evaluation criteria, in the group of inexperienced specialists there are $13 \%$ and $11 \%$ fewer people with high and medium levels of stress resistance, but $17 \%$ more with a satisfactory level than in the group of experienced with an unsatisfactory level of stress resistance. At the same time, this group has all the strategies to overcome stressful situations, which are manifested for experienced rescuers (according to the method of "Overcoming stress").

At the same time, significant differences in indirect indicators of stress resistance, on the one hand, positive - more pronounced than in the experimental group, indicators of general internality, internality in interpersonal relationships, internality of health, as well as interest, activation; on the other hand, a higher level of personal anxiety led to a worse level of comfort and rather negative manifestations of social maladaptation due to significantly higher rates of addictive behavior and suicidal risk.

For inexperienced rescuers, strategies of passivity, avoidance, manipulation, antisocial strategies - harsh, dogmatic, cynical, inhumane actions, aggressive strategy (negativism, rivalry, confrontation, pressure, refusal to find alternative solutions) proved to be more typical. Inexperienced rescuers are more likely to show social timidity, insecurity, and at the same time in stressful situations, their behavior is more antisocial and aggressive towards others. Obviously, the latter is a manifestation of the compensatory mechanism of overcoming internal discomfort or overcoming psychological complexes of self-doubt and negativity towards the environment (Kostetska et al., 2020).

To clarify the characteristics of stress-resistant and non-stress-resistant individuals and the characteristics of typical profiles, we made comparative characteristics of the stress resistance components. The comparative analysis was performed according to the data obtained 
through the use of a set of methods for studying direct and indirect indicators (in six groups of stress-resistant and non-stress-resistant rescuers, servicemen, and students).

Typical profiles of stress-resistant and non-stress-resistant individuals by structural components of stress resistance are presented in fig.1.

Analysis of the profiles of stress-resistant and non-stress-resistant individuals, presented on a 9-point scale, showed that there are significant differences between them, both in terms of informative factor components and in the integrated final data of the structural components of stress resistance.

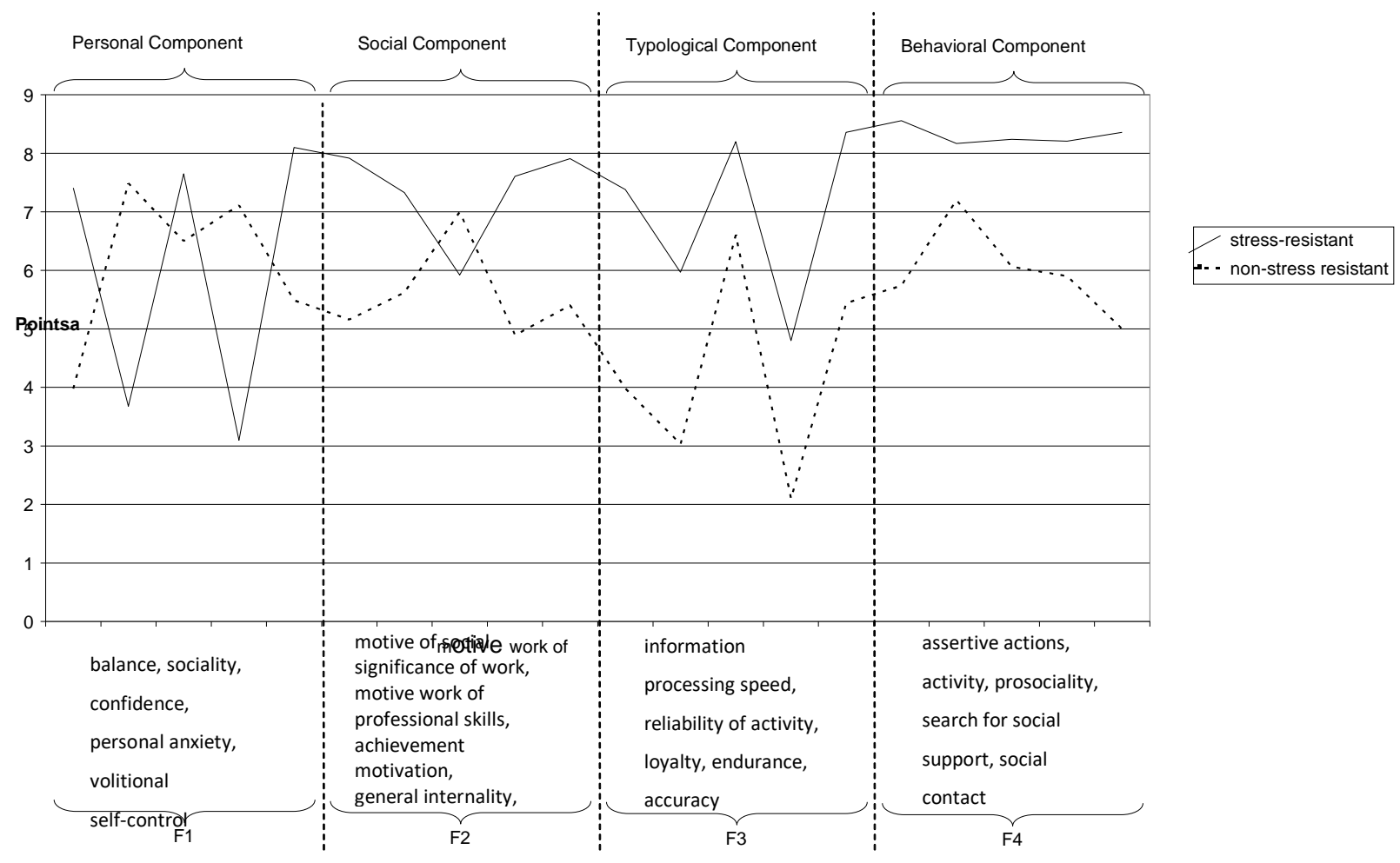
Fig.1 Profiles of stress-resistant and non-stress-resistant individuals by structural
components of stress resistance

Thus, for the typical profile of stress-resistant individuals, the equilibrium index is at the level of 6.84-7.41 points, which is almost twice the same data in non-stress-resistant individuals at $p<0.05$. The level of shyness (stress sensitivity) is 2-2.5 times lower than in groups of nonstressful people. Stress-resistant people are characterized by a high level of confidence and 
strong-willed self-control, a low level of personal anxiety. At the same time, for non-stressresistant individuals these parameters are opposite - a low level of self-confidence and will selfcontrol, a high level of anxiety.

According to the 9-point scale of the social factor, typical characteristics for stressresistant people are high level of a motive of the social significance of work, professional skills, general internality, and readiness for activity (8.21-7.18 points), which was 2-3 points higher than for non-stress-resistant ( $\mathrm{p}<0,05)$. Thus, the motive of achievement for stress-resistant people is at the level of 5,92 $\pm 0,49$ points, and for not stress-resistant persons - 6,99 $\pm 1,17$ points.

Informative components of the typological factor for the typical profile of stress-resistant individuals are represented by a significantly higher level (2-3 points) than for the profile of non-stress-resistant individuals. Thus, a stress-resistant personality is characterized by a high level of lability, functional mobility, and endurance of the nervous system. For persons with a low level of stress resistance, there are significantly lower these characteristics, which leads to insufficient plasticity of the functioning of each of the typological factor components and a decrease in stress resistance of the individual.

A comparative analysis of the behavioral factor components revealed that stress-resistant individuals are characterized by a high level of assertiveness, prosociality, social support, social contact, which is 2-3 points higher than for non-stress-resistant individuals (Kvitka et al., 2019).

Profiles of stress-resistant and non-stress-resistant individuals according to the integrated indicators of factors F1, F2, F3, F4 are presented in fig.2.

The typical profile of stress-resistant individuals on a 9-point scale is characterized by the expression of the personal factor (F1) at the level of $6.69 \pm 0.5$ points; social (F2) - $7.45 \pm 1.01$ points; typological (F3) - $6.84 \pm 0.9$ points and behavioral (F4) $-8.23 \pm 1.3$ points. For nonstress-resistant individuals, respectively: F1 - $3.76 \pm 0.39$ points; F2 - $5.54 \pm 0.78$ points; F3 $4.04 \pm 0.48$ points; F4 $-5.05 \pm 0.83$ points. Significantly lower parameters of the factor structural components of stress resistance according to the typical profile cause significantly worse direct indicators for non-stress individuals (3.06 \pm 0.05 points - integral stress resistance and $7.01 \pm 0.72$ points - integral stress sensitivity). 


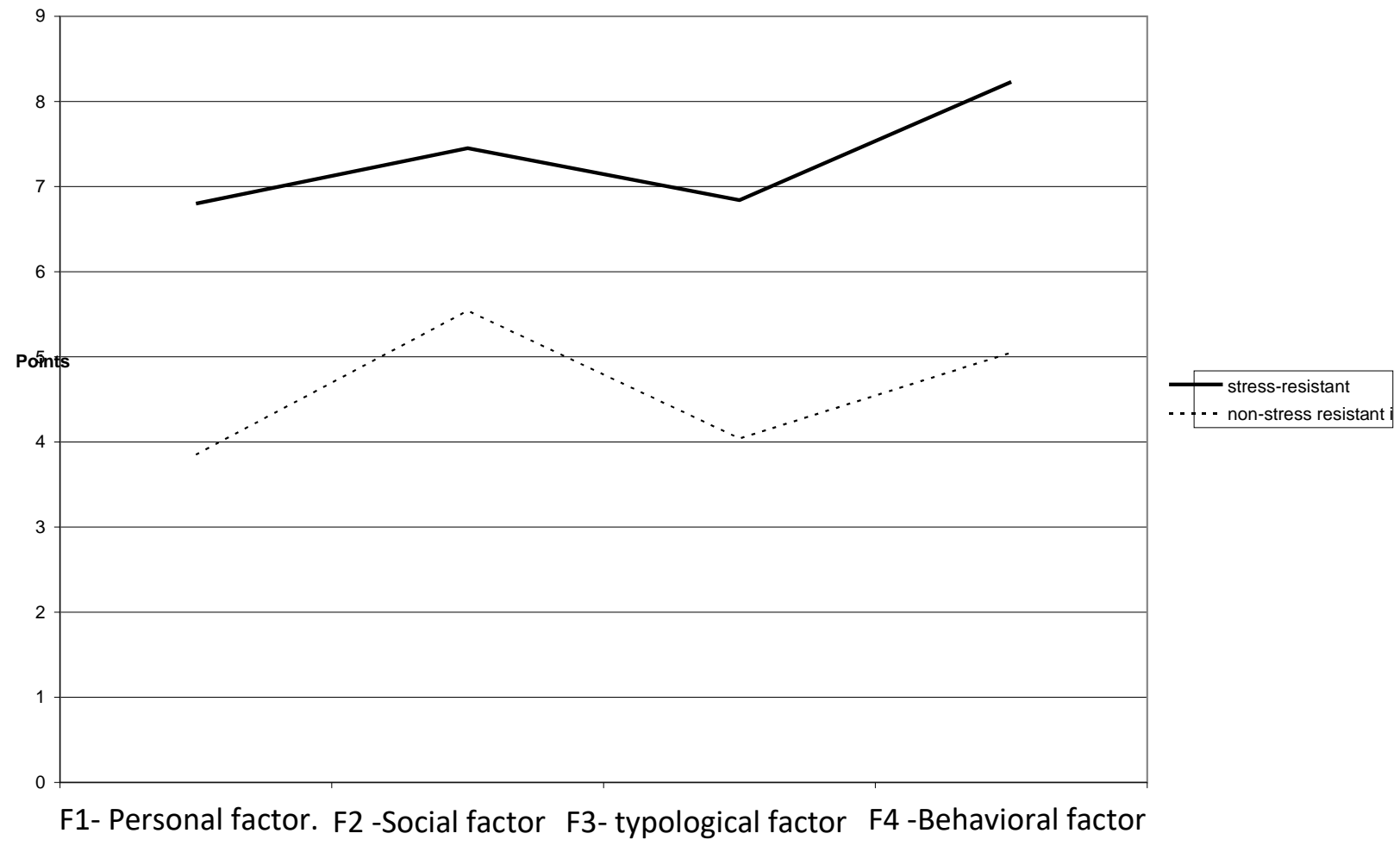

Fig. 2 Profiles of integrated indicators of factors F1, F2, F3, F4 for stress-resistant and non-stress-resistant individuals

As a result, it was found that the level of stress resistance in direct terms is interrelated with the peculiarities of the manifestations of its factor structural components of personal, social, typological, and behavioral spheres, which determine the specifics of typical profiles.

We determined the levels and features of stress resistance manifestations by factor components for stress-resistant and non-stress-resistant individuals according to the results of comparative analysis. For stress-resistant individuals, the direct indicators are characterized by high and medium levels with significantly lower results of integral, basic and dynamic stress sensitivity. According to the personal component (F1), the typical profile is characterized by a high level of balance (stress resistance), low level of stress sensitivity according to the FPI method; according to the personal differential, a high level is marked by a scale of confidence and activity, characterized by low personal and situational anxiety, a high level of emotional and volitional self-control (persistence, self-control). At the same time, the opposite patterns are observed for non-stress-resistant individuals - a significantly lower level of direct indicators of stress resistance both in comparison with stress-resistant individuals and in comparison with the average interpretive criteria of the relevant methods.

According to the social component of stress resistance (F2), motivational components were the most important for stress-resistant individuals - motives of social significance and professional skills (high indicators); moderately expressed indicator of motivation to achieve, significantly expressed general and professional internality, readiness for activity. Peculiarities of non-stress-resistant people are that the indicators of the motive of self-affirmation and the 
motive of work turned out to be significantly higher, and the indicators of the motive of achievement were lower.

According to the typological factor for stress-resistant individuals, it should be noted the high level of functional mobility of nervous processes, which determines the speed of information processing; reliability of activity, characterized by a combination of functional mobility and endurance, which is determined by the strength of nervous processes, expressed at the average level, and the average level of endurance as the force of nerve excitation and endurance of nerve cells to long-term stimuli, high lability of nervous processes forces of nervous processes. Peculiarities of non-stressful individuals are manifested in the low level of functional capabilities of the nervous system, which determine endurance, productivity; the speed of information processing, accuracy, which along with mostly medium and low lability of nervous processes and medium and weak nervous system causes low stress.

Behavioral factor in the structure of stress resistance for stress-resistant individuals is characterized by a high level of assertiveness, activity, prosociality, the search for social contacts, and social support. For non-stressful individuals, significant differences are that among the behavioral strategies for overcoming stress, the most important are manipulative actions, actions with avoidance, aggressive actions.

Thus, we determined and characterized the components of personality stress resistance and typical profiles of stress-resistant and non-stress-resistant individuals of different examined categories by structural components of stress resistance.

\section{Conclusions}

We found that the typical profile of stress-resistant individuals by components is characterized by a high level of balance, that is resistance to stress, confidence and activity, emotional and volitional self-control, low levels of stress, personal and situational anxiety, high motivation, general and professional readiness. to activity, a high level of functionality of the nervous system. Stress-resistant individuals are characterized by a high level of assertiveness, activity, prosociality, the search for social contacts and social support. At the same time, the typical profile of non-stressful individuals is characterized by inverse patterns - a significantly lower level of direct and indirect indicators of stress resistance, among the behavioral strategies for overcoming stress typical were manipulative actions, avoidance actions, aggressive actions.

\section{Reference}

Bodrov V.A. (2003). Workshop on differential psychodiagnostics of professional suitability. M.: PER SE.

Cohen, S., \& Williamson, G. M. (1991). Stress and infectious disease in humans. Psychological bulletin, 109(1), 5 .

Gichun V.S. et al. (2019). Stress-associative health disorders under the conditions of armed conflict. Dnipro: Accent PP.

Hobfoll, S. E. (1989). Conservation of resources: A new attempt at conceptualizing stress. American psychologist, 44(3), 513.

Korolchuk M.S., Krainyuk V.M. (2012). Socio-psychological support of activity in normal and extreme conditions. $\mathrm{K}$.: Nika-Center.

Kostetska, K., Khumarova, N., Umanska, Y., Shmygol, N., \& Koval, V. (2020). Institutional qualities of inclusive environmental management in sustainable economic development. Management Systems in Production Engineering, 28 (2), 15-22. 
Krainyuk V.M. (2007). Psychology of personality stress resistance. K.: Nika-Center.

Kvitka, S., Starushenko, G., Koval, V., Deforzh, H., \& Prokopenko, O. (2019). Marketing of Ukrainian higher educational institutions representation based on modeling of Webometrics Ranking. Marketing and Management of Innovations, 3, 60-72. http://doi.org/10.21272/mmi.2019.3-05

Lazarus R.S. (1993). Coping theory and research: Past, present, and future. Psychosomatic Medicine, 55, 234-247.

Parker J. D. A., Endler N. S. (1996). Coping and Defence: A Historical Overview. Handbook of coping: theory, research, application. New York: John Wiley and Sons, pp. 3-23.

Perrez M., Reicherts M. (1992). Stress, Coping, and Health. A Situation-Behavior Approach. Theory, Methods, Applications. - Seattle; Toronto; Bern; Gottingen: Hogrefe \& Huber Publishers, pp. 125-128.

Sadovii V.P., Timchenko O.V. (ed.) (2017). Actual researches in modern national extreme and crisis psychology. NUTZU. H . Mezina.

Shcherbatykh, Y. V. (2000). Self-regulation of autonomic homeostasis in emotional stress. Human Physiology, 26(5), 641-642.

Timchenko O.V. (ed.) (2007). Extreme Psychology. K .: LLC "August Trade".

Yankovyi, O., Koval, V., Trokhymets, O., Karpenko, M., \& Matskevich, Y. (2020). Economic assessment of investment on the basis of production functions. Turismo: Estudos \&Práticas, 2. 